\title{
ARAGUAIA-XINGU: REFLEXÕES AOS DESAFIOS SOBRE O DESENVOLVIMENTO SUSTENTÁVEL REGIONAL
}

\author{
ARAGUAIA-XINGU: REFLECTIONS ON REGIONAL SUSTAINABLE DEVELOPMENT \\ CHALLENGES
}

\section{Iberê Martí Moreira da Silva}

Graduado em Engenharia Florestal pela Universidade do Estado de Mato Grosso (UNEMAT). Mestre em Ciências Florestais e Doutor em Ciências: Plantas Medicinais, Aromáticas e Condimentares pela Universidade Feral de Lavras(UFLA).

E-mail: iberemarti@gmail.com

Resumo: O Norte do Araguaia é a região com maior quantidade de assentados Estado de Mato Grosso e que, tem maior área percentual destinada assentamentos da Reforma Agrária. Esses assentamentos foram constituídos ao longo do século XX, impulsionados pela demanda dos Agricultores Familiares (posseiros, camponeses e indígenas) e as políticas governamentais de ocupação do território. O objetivo desse texto é realizar uma análise histórica do Norte do Araguaia, baseada nas características da econômicas, sociais e ambientais, que permitam avaliar, quanto aos desafios, as oportunidades, as fragilidades e as ameaças relacionadas a promoção do desenvolvimento sustentável regional. A metodologia utilizada foi através da coleta de dados secundários, do Censo Agropecuário do IBGE e artigos científicos. Nesta perspectiva foi identificado o pilar da economia regional, que é basicamente agropecuária, e a divisão do território, onde foram identificados como ponto forte os assentamentos da Reforma Agrária. Foi possível observar dois conceitos de desenvolvimento antagônicos, o da agricultura empresarial, na exportação de commodities versus Agricultura Familiar e indígena, para a produção de alimentos para demanda interna e voltados promoção da Soberania Alimentar. No decorrer da discussão foi realizada uma caracterização histórica, ambiental, social e econômica regional, com a perspectiva de buscar soluções para os principais desafios enfrentados pela população. E através desses realizar apontamentos sobre as estratégias de desenvolvimento sustentável do território, que devem buscar melhorar as atividades agropecuárias; o fortalecimento instituições públicas e privadas de ensino, pesquisa e extensão; resolver os passivos ambientais, recuperação de áreas de preservação permanente; diversificar a economia, com agroindustriais e turismo.

Palavras Chave: Reforma Agrária; Agricultura Familiar; Agricultura empresarial; políticas públicas; e Extensão Rural Inovadora.

Abstract: The region of the North Araguaia has the highest number of settlers in the state of
Mato Grosso, and the larger percentage area destined to Agrarian Reform settlements. These
settlements were formed throughout the 20th century, driven by the demand of family farmers
(squatters, peasants and indigenous people) and government policies of land occupation. The
objective of this study is to carry out a historical analysis of the North of Araguaia region, based
on the economic, social and environmental characteristics that allow for an evaluation of the
opportunities, fragilities and threats related to the promotion of regional sustainable
development. The methodology was based on the collection of secondary data, the agricultural
census of IBGE and scientific articles. In this perspective the pillar of the regional economy,
which is basically agricultural and livestock, and the division of territory were identified, where
the agrarian reform settlements were identified as a strong point. It was possible to observe two 
antagonistic concepts of development, that of business agriculture, in the export of commodities, versus family and indigenous agriculture, for the production of food for internal demand and aimed at the promotion of food sovereignty. During the discussion a historical, environmental, social and economic characterization of the region was carried out, with the perspective of seeking solutions to the main challenges faced by the population. And through these make notes on the strategies of sustainable development of the territory, which should seek to improve agricultural activities; the strengthening of public and private institutions for teaching, research and extension; resolving environmental liabilities, restoring permanent preservation areas; and diversifying the economy; with agro-industrial and tourism.

Keywords: Agrarian Reform; Family Agriculture, Business Agriculture; Public Policies; and Innovative Rural Extension.

\section{Introdução}

O Norte do Araguaia é a região com maior quantidade de assentados Estado de Mato Grosso e que, tem maior área percentual destinada assentamentos da Reforma Agrária. Esses assentamentos foram constituídos ao longo do século XX, impulsionados pela demanda dos Agricultores Familiares (posseiros, camponeses e indígenas) e as políticas governamentais de ocupação do território.

A região tem características ambientais peculiares, como as áreas alagadas, que apresentam grande biodiversidade e fragilidade. E que proporcionam a região belezas cênicas singulares. Essas paisagens são alteradas e/ou substituídas, principalmente pelas atividades agropecuárias, como a pecuária extensiva e agricultura de subsistência. No entanto, principalmente a partir da década de 2000, vem sendo ocupada também pela agricultura empresarial (neste texto adotamos o mesmo termo utilizado pelo governo brasileiro).

Então as condições sociais, econômicas e ambientais do território são modificadas, e existe um conflito entre dois conceitos de desenvolvimento. Os agricultores familiares que ocuparam o território ao longo do século XX e a agricultura empresarial. Os primeiros, os Agricultores Familiares, têm como características a pequena propriedade, a mão-de-obra familiar e a produção de alimentos voltados a consumo próprio e ao mercado interno, promovendo a Soberania Alimentar. A agricultura empresarial é baseada no monocultivo, latifúndio, utilização de maquinários automatizados e pouca mão-de-obra e exportação de commodities.

Na região Norte do Araguaia é possível observar as rápidas transformações que a Globalização, e a economia, provocou em menos de quatro décadas. Se antes, o processo de ocupação territorial demorava séculos, atualmente a tecnologia permite o avanço das atividades econômicas em questão de anos, até mesmo meses. Anteriormente utilizavam machados, agora 
máquinas automatizadas, que realizam as práticas que culminam na substituição das paisagens nativas. A questão é a técnica e é técnica (Santos e Silveira, 2006).

A região Norte do Araguaia está sendo incorporada ao mercado global de commodities, através da agricultura empresarial, o que provoca diversos conflitos com a Agricultura Familiar, principalmente na disputa de recursos e estrutura do Estado. Mas quais transformações essas mudanças provocam e qual o planejamento estratégico para as alterações sociais, ambientais e econômicas que resultam desse processo? O objetivo desse texto é realizar um histórico da região, fazendo alguns apontamentos, quanto aos desafios, as oportunidades, as fragilidades e as ameaças relacionadas ao processo ocupação do território, e os diferentes conceitos de desenvolvimento regional, nesta que é uma das últimas fronteiras (agrícolas?) do Brasil.

\section{Metodologia}

A metodologia utilizada foi através da coleta de dados secundários do Censo Agropecuário IBGE de 2017, e em artigos científicos na base de dados, Scielo.Org, utilizando palavras chave como, "norte do Araguaia"; "Araguaia-xingu", "Vale do Araguaia" "Baixo Araguaia", além dos nomes dos municípios que compõe o território: Alto do Boa Vista, Bom Jesus do Araguaia, Canabrava do Norte, Confresa, Luciara, Porto Alegre do Norte, Novo Santo Antônio, São Felix do Araguaia, São José do Xingu, Santa Cruz do Xingu, Santa Terezinha, Serra Nova Dourada, Vila Rica. Foi então realizado o filtro dos artigos que tem assunto relacionados a temáticas sociais, ambientais e econômicas regionais.

E identificado o pilar da economia regional, que é basicamente agropecuária, e a divisão do território, onde observamos como ponto forte os assentamentos da Reforma Agrária, e avaliar os dois conceitos de desenvolvimento que são antagônicos, o da agricultura empresarial - latifúndio, monocultivo, exportação de commodities - versus os assentamentos da Reforma Agrária - agricultura familiar e indígena, pautado na mão-de-obra familiar, produção de alimentos para atender a demanda interna e voltados a promoção da Soberania Alimentar. Levando em consideração esses interesses conflituosos, foi ponderado ao longo do texto, as características e as forças políticas e econômicas que disputam, tanto o subjetivo (a narrativa) quanto os objetivos materiais e estruturais, na consolidação do seu respectivo projeto, e portanto, conceito de "desenvolvimento sustentável”.

O que sustenta a metodologia adotada é, portanto, a literatura clássica da Globalização como processo de ocupação territorial, através de mecanismos complexos e os respectivos 
interesses das empresas transnacionais e multinacionais, e a visão do território que é ocupado, através da observação empírica in loco, e as respectivas transformações no local, que tem que assimilar incorporar esse processo.

\section{0 ambiente no território Norte do Araguaia}

No pulsar lento das águas, a região Norte do Araguaia -entre os rios Araguaia e o Xingu- na bacia hidrográfica definida pelo regime fluvial, de um lado a Serra do Roncador, e do outro, pela Ilha do Bananal. Em altitude que varia entre 150 metros (terras baixas) e 400 metros (terras altas) do nível do mar, em que nas partes mais baixas, atravessando o mosaico que transita entre longas planícies alagadas e seus murundus, cujo nível do lençol freático é alto, ou seja, próximo a superfície. E, entre as terras altas, no entanto planas, por onde "nascem" as águas que descem, escorrendo lentas, devagar, quase paradas, principalmente no período de seca e menor vazão, entre junho a outubro (Martins et al., 2006). Eis que o regime fluvial confere características peculiares a biodiversidade da região, com diversos ecótonos e que variam bastante em escalas de pequenas distâncias, que são definidas principalmente pelas características químicas (os minerais) e físicas (textura, profundidade, entre outras) do solo, além de matéria orgânica, altitude, declividade e etc.

A vegetação das planícies alagadas, com gramíneas naturais e murundus com vegetação do cerrado, apresentam aspectos característicos (Martins et al., 2006), e são classificados como áreas de importância biológica extremante alta (Marimom et al., 2012). Essas áreas, em alguns casos, são substituídas tanto pela pastagem exótica, quanto porcultivos de grandes culturas, de milho e soja. Para tais fins são abertos canais de drenagem, que modificam, alteram o regime fluvial. As áreas altas, que também apresentam baixa altitude (em relação ao nível do mar) e topografia levemente plana, onde existem variações do cerrado até florestas, também são convertidas em áreas de pastagens e lavouras.

\section{A ocupação do território Norte do Araguaia}

O Norte do Araguaia (ou Vale do Araguaia, ou Baixo Araguaia), como citaram Garbin e Silva, (2006), intitulado neste texto aos limites da região nordeste do Estado de Mato Grosso, que no início do processo de ocupação territorial, teve como principal atividade econômica a pecuária extensiva com pastagem nativa, manejadas pelos retireiros, através do uso do fogo e pelo regime fluvial (cheias e secas). Esses migrantes vieram de diversas regiões do país, no 
passar do século XX, em busca de terra e melhores condições de vida, e/ou incentivados por políticas governamentais, foram ocupando o território que antes era habitado por índios, principalmente os Tapirapé, Xavante e Karajá (Garbin e Silva, 2006).

Os primeiros migrantes tiveram como maior dificuldade o acesso e a locomoção. E chegaram a região pelo rio, de barco, ou por terra, a pé e/ou com ajuda da tração animal. A construção das estradas, por iniciativas do governo federal, intermediado pela Superintendência de Desenvolvimento da Amazônia (SUDAM) no projeto, cujo slogam foi "Integrar para não entregar”, entre as décadas de 1970 e 1980, deu uma nova dinâmica a região. Uma questão é que a pavimentação asfáltica não chegou até o final do projeto inicial, no caso a BR-158, o que manteve o Norte do Araguaia de certa forma isolado, devido à dificuldade de acesso.

As estradas de terra, nessa região que chovia aproximadamente 2.000 milímetros anuais, entre os meses de outubro a março, constantes e lentas, durando semanas sem estiar, eram fatores limitantes ao transporte terrestre. (Cabe observar que as características pluviométricas modificaram ao longo dessas décadas, alterando o regime pluvial). Mesmo diante das dificuldades, a região foi sendo ocupada por esses resistentes migrantes, de diversas regiões do país, que chegaram com seus sonhos e famílias, em busca de terra para praticar atividades agropecuárias, e outros para trabalhar em fazendas ou empresas de atividades agrícolas da região. As usinas de cana-de-açúcar, incentivadas pelo governo federal através de programas de incentivo aos biocombustíveis, o Proálcool (Garbin e Silva, 2006), necessitou de pessoas para trabalhar e fomentou a ocupação dessa região, um exemplo, entre diversas outras atividades econômicas.

Apesar da baixa densidade populacional, aos poucos, no decorrer do século XX, e em especial nas décadas de 1980 e 1990, as terras foram sendo ocupadas por pequenos e médios agricultores, conhecidos na região como posseiros. Uma atividade econômica da época era a cultura da banana, que apesar das perdas devido as condições de transporte, garantiram produtividade e movimentavam a economia. Com a doença dos bananais, no início da década de 1990, e a falta de tecnologias e técnicas, essa atividade econômica foi praticamente extinta na região.

Nesse período também eram cultivados alimentos para suprir as necessidades da família, conhecida como agricultura de subsistência, que utiliza trabalho manual e poucos (ou nenhum) insumos (externos a propriedade). Eram cultivados principalmente a mandioca, arroz, feijão, milho e outros. 
Mas com a chegada da agricultura empresarial aos países em desenvolvimento, na região Norte do Araguaia a partir da década de 2000, que é mecanizada e automatizada, de um modo progressivo em um mesmo mercado, cada vez mais unificado (Mazoyer e Roudart, 2010). Como revela Ziegler (2010), as empresas multinacionais ou transnacionais controlam a cadeia produtiva alimentar - desde a semente, insumos, armazenamento, processamento e venda. Utilizam também biotecnologia, a larga escala de produção, os altos financiamentos e investimentos públicos e privados, e ainda as políticas públicas de incentivo (como exemplo a Lei Kandir) e pressões políticas através de leis restritivas (como as "certificações" e a "vigilância as condições sanitárias"), entre outras. Ações que culminam por inviabilizar a agricultura de subsistência. que perde a capacidade competitiva, pela relação da produtividade do trabalho quando comparada a agricultura empresarial (Mazoyer e Roudart, 2010), e a região passou a importar esses produtos (arroz, feijão, et.) - fenômeno que é mundial.

Ocorreu então, uma reorganização das atividades agrícolas no Norte do Araguaia, e a pecuária de corte e leite passaram a ser a principal atividade econômica, entre os pequenos e médios agricultores (Garbin e Silva, 2006), numa substituição da agricultura de subsistência pela agricultura de excedentes.

\section{Conflitos: a disputa pelo uso e ocupação do solo no Norte do Araguaia}

Diante da grande quantidade de terras devolutas da União, instalou-se diversos conflitos entre os latifundiários e as empresas multinacionais versus posseiros e indígenas. A Constituição de 1988, que garante "o uso social da terra", buscou a resolução dos conflitos, por intermédios de organizações governamentais oficiais, como INCRA (Instituto Nacional de Colonização e Reforma Agrária), e a INTERMAT (Instituto de Terras de Mato Grosso), e organizações não governamentais, juntamente com a Igreja Católica - Prelazia de São Félix do Araguaia -, através da distribuição de terras aos posseiros por meio de assentamentos da Reforma Agrária.

A quantidade de assentamentos criados para suprir a demanda daquela época, conferiu uma peculiaridade ao Norte do Araguaia, em relação as demais regiões do estado de Mato Grosso, ter o maior percentual de terras com entre pequenos agricultores familiares (até 320 hectares, ou quatro módulos fiscais) e maior quantidade de assentados, como mostram os dados do IBGE (2017) para municípios como Confresa, Vila Rica, Bom Jesus do Araguaia, Porto Alegre do Norte, Canabrava do Norte, respectivamente. A pergunta é, por que o Norte do Araguaia tem essa peculiaridade (\% de território em assentamentos) em relação as demais do 
estado, sendo que foram ocupadas na mesma época? Essa configuração do território, é difícil imaginar possível sem a atuação e presença do bispo D. Pedro Casaldáliga, que para além do exemplo prático e das ações concretas, é um dos maiores intelectuais do século XX.

Nessas propriedades da Reforma Agrária, por questões tecnológicas, técnicas e culturais a atividade principal é a pecuária, de corte ou de leite. O gado possibilita uma série de vantagens para uma região com dificuldades em logística e transporte. O manejo das pastagens e do gado é simples, a tecnologia é básica e exige pouco conhecimento específico, e o mercado é (mais) sólido, permitindo a venda de acordo "com as necessidades da família ou (melhor) valor de mercado" - ao contrário de culturais anuais que cultivavam anteriormente.

A demanda por produtos da Agricultura Familiar também não contribuir para impulsionar a mesma. Apesar da região ser cortada por estradas que são vias estratégicas que interligam a outros estados e tornando-a via terrestre da logística de commodities para exportação, mesmo assim fica longe - distância em km - dos grandes centros (o que aumenta custo com logística) e considerando demanda versus oferta o consumo é pouco, devido à baixa densidade populacional, as poucas políticas públicas estratégicas a curto, médio e longo prazo e a competição com os preços praticados pela agricultura empresarial. Esse contexto novamente favorece a atividade pecuária, como uma forma de resistência do Agricultor Familiar.

No entanto, com passar dos anos, duas ou três décadas, foi possível observar que as pastagens degradadas, com solo compactado e inférteis, inclusive pelo uso de técnicas inadequadas, como é o uso do fogo - prática que diminuiu devido as ações de extensionistas e a fiscalização, mas que ainda existem - ou piquetes grandes, extensos, que compactam o solo e inviabilizam as gramíneas exóticas, tendo que realizar reformas a cada três ou quatro anos, o que aumenta (em demasia) o custo de produção; além da falta de acesso a tecnologias inovadoras, que garantiriam maiores produtividade, como exemplo, o Pastoreio Racional Voisin (Machado, 2013), e a baixa assistência técnica e extensão pelos órgãos públicos. A maioria da assistência técnica é realizada pelas empresas privadas que tem por objetivo a venda dos seus insumos, conjugadas com gratificações aos vendedores. Até mesmo questões administrativas básicas, como a supracitada, "vender (o gado) de acordo com a necessidade", como exemplo, é empírica e pode não ser viável. Ou mesmo questões técnicas relacionadas ao cultivo e manejo de pastagens (Machado, 2013).

Um bom pecuarista é, antes de tudo, um bom agricultor. Novamente, os exemplos mostram que, a agricultura de subsistência ou de excedentes (os pequenos agricultores familiares) é refém de um processo muito aquém das suas necessidades (e realidade) políticas, técnicas e tecnológicas. É necessário que haja a produção de tecnológicas e técnicas, sociais e 
inovadoras, especificas para os agricultores da região. Exemplos, poderia citar as pastagens nativas (e ecológicas) nos pampas e no pantanal, que garantem ao produto uma qualidade diferenciada e que agrega valor de mercado e que preservam a biodiversidade. No entanto, é necessário políticas estratégicas direcionadas a esta finalidade na região do Araguaia-Xingu.

Esses assentamentos da Reforma Agrária convivem com a agricultura empresarial, caracterizadas por quatro pilares que remetem as atividades econômicas do país, desde o Brasil colonial, sendo eles: o latifúndio (áreas extensas); o monocultivo (cana-de-açucar, soja, milho, gado); a pouca mão-de-obra e de baixo custo; e produzir commodities (matéria prima ou semiindustrializada) para exportação. A agricultura empresarial por suas vantagens relativas e incentivos governamentais, tem acesso as inovações tecnológicas (e a técnica?), a cada dia mais automatizadas e mecanizadas, necessitando de menos trabalhadores e que sejam qualificados, tanto para operar quanto para manutenção desses equipamentos.

Importante ressaltar que os conflitos supracitados persistem, portanto, a disputa pela terra é permanente, e em muitos casos vem sendo intermediados pelo estado através da justiça ou mesmo pelo órgão de fiscalização e regularização fundiária. Mas novas formas de pressão e tensão, exercida nesses conflitos é a utilização, e consequente deriva, de insumos (agrotóxicos, como herbicidas, fungicidas, inseticidas) pela agricultura empresarial, como existem diversos relatos e denúncias de agricultores familiares e camponeses e indígenas, onde deveriam ser criadas zonas de amortecimento como solução política e técnica, restringindo e/ou proibindo uso desses insumos. Possibilitando, assim, a viabilidade das atividades produtivas dos assentados.

Sem a criação de políticas estratégicas para garantir a permanência do pequeno agricultor na terra, o êxodo rural persistirá. Apesar de o Censo agropecuário do IBGE de 2017 revelar que muitos filhos dos agricultores familiares voltam para viver da terra quando tem entre 30 e 40 anos de idade. Mas existe uma política pública especifica voltadas a juventude rural no estado de Mato Grosso? Contudo o Censo também mostra que as pequenas e médias propriedades diminuíram em quantidade na última década no Brasil, enquanto as propriedades acima de 1000 hectares aumentaram, inclusive as terras em nome de pessoa jurídica (empresas) - que alteram as formas de conflitos-, além do arrendamento de terras que também vem num crescente; e que o número de trabalhadores rurais diminuiu, enquanto o uso de maquinário aumentou. Além do aumento no arrendamento de terras, inclusive pelas pessoas jurídicas supracitadas.

Mas esses dados também revelam que mais de $70 \%$ do alimento que chega à mesa do brasileiro, e que faz parte da cesta básica, é proveniente da agricultura artesanal, camponesa, 
indígena, quilombola e/ou familiar. Portanto são fundamentais para alimentação da população. A própria produção de gado, por diversos pequenos agricultores, é um fator importante na dinâmica de competição, aquece o mercado interno, e que ao mesmo tempo promove o equilíbrio do preço desse produto, ou seja, da economia local, o que tende a perder esse equilíbrio, com o provável aumento de preço ao consumidor final, caso venha a se constituir monopólios. Mas como se dá a comercialização desses produtos (carne, leite e derivados) por esses agricultores? (De forma individual, cooperativa, entre outras). E o processamento desses produtos? Existem agroindústrias na região?

Uma questão central que deve ser colocada como prioritária nas políticas públicas regionais, é a Soberania Alimentar. A soberania na questão alimentar que garanta ao agricultor autonomia na produção, distribuição e consumo dos alimentos. A soberania alimentar enquanto estratégia de desenvolvimento social, econômico e ambiental do Norte do Araguaia. Pois o fenômeno das periferias brasileiras, e todos os seus desdobramentos (falta e/ou condições precárias de habitação, saneamento básico, escola, saúde, e a consequente violência), tem relação direita com o modelo de desenvolvimento territorial "escolhido" (Santos e Silveira, 2006). Qual violência é estrutural? Aquela que obriga abandonar sua cultura, migrar para locais desconhecidos, com poucos empregos, baixos salários, etc. Qual seria a solução para esses problemas (estruturais)?

\section{A incorporação do território Norte do Araguaia ao mercado global}

Até o início do século XXI, poucos eram os meios de transportes automotores na região, com alguns improvisados de motor de dragas e a carcaça de carros, que denominavam paco-paco (devido ao som produzido pelo motor), ou mesmo as antigas gaisera (carros adaptados ao gás, devido ao custo e dificuldade de acesso a outros combustíveis), o transporte hegemônico era de tração humana, a bicicleta, e animal, o cavalo e o carro de boi. Que iam construindo, improvisadas, estradas cheias de curvas, por entre cerrado e varjão, desviando de cupins, árvores e murundus.

Porém nos dias atuais, circulam desde camionetes a caminhões de última geração; de maquinários e implementos agrícolas, até aviões e drones para cultivo e manejo das lavouras; além de silos e secadores para armazenamento de grãos. A expansão das atividades econômicas, de interesses de grandes corporações nacionais e internacionais, trouxe consigo maior presença do Estado, principalmente no que se refere a infraestrutura e logísticas, como exemplo, as obras 
de pavimentação asfáltica de estradas, ou mesmo maior manutenção das vias terrestres sem asfalto.

Nas décadas de 1980, 1990 e 2000 foram executados importantes projetos na área educacional para o Norte do Araguaia, atendendo a demandas especificas, o projeto INAJ $A^{1} \mathrm{e}$ as PARCELADAS ${ }^{2}$.

1 O Projeto Inajá foi parceria entre Universidade Estadual de Campinas, Unicamp, com apoio das prefeituras, da Secretaria de Educação, SEDUC, e da Igreja Católica, com objetivo de capacitar professores para ministrar aulas no magistério em Mato Grosso.

${ }^{2} \mathrm{O}$ Programa de Licenciatura Plenas Parceladas são iniciativa da UNEMAT (Universidade do Estado de Mato Grosso) para atender a demanda na formação de professores para rede de educação do Estado de Mato Grosso.

No entanto ainda é incipiente e tímidas as iniciativas nas áreas de educação, saúde e segurança, como a construção de escolas e creches (em tempo integral), universidades, institutos, centro de pesquisa e extensão; hospitais; postos de fiscalização de rodovias e serviços de inteligência estratégica em segurança. Mais tímidas ainda as ações estratégicas que interliguem e conectem essas áreas, como exemplo serviços de capacitação e de pesquisa relacionadas a inovação em saúde e segurança e educação.

Os estudos sobre a região são escassos, alguns relatam o ambiente, mas no que se refere ao social e econômico pouco tem se feito, apesar do estudo estratégico produzido pelo Ministério do Desenvolvimento Agrário, datado de 2006, conduzido por Garbin e Silva. Como podem então criar políticas estratégicas sem conhecer a fundo a realidade? O Estado vem atendendo demandas pontuais e coorporativas, geralmente (ou a maioria) canalizadas aos determinados grupos de maior poder econômico.

A impressão que se tem é que falta um planejamento estratégico, um projeto de desenvolvimento para o Norte do Araguaia. Cidades polos fazem parte de processo de (des)ordenamento territorial, sendo possível observar o mesmo fenômeno, em diferentes escalas de espaço e tempo ao longo da história do Brasil (Santos, 2012).

Assim, nas cidades que se tornam polo em serviços, e consequente de atividades comerciais mais diversas, e também o aumento da violência, que não é condizente com os investimentos do Estado em segurança - tanto em nível federal, quanto estadual, e municipal. Como exemplo, tem-se o aumento do fluxo de cargas de escoamento da produção de grãos e, das atividades de serviços relacionadas ao setor de transporte, que criam demandas especificas de responsabilidade do Estado, e que muitas vezes são negligenciadas.

Essa configuração é um retrato da história do Brasil ao longo dos séculos, onde a falta de um ordenamento territorial, de uso e ocupação de solos urbanos e rurais, que beneficie e inclua a maioria da população, e que promoveram a formação de grandes periferias urbanas (Santos e Silveira, 2006). 
No entanto, no Norte do Araguaia temos uma configuração singular, diferente de muitas outras regiões do estado e do país, e que deve ser priorizada. É preciso compreender que esses agricultores familiares, camponeses e indígenas que se estabeleceram, e que resistem, depois de tantas dificuldades - na logística; os conflitos pela posse da terra; falta de serviços saúde, educação e assistência técnica; entre outras - tem uma forte identidade com a região. Os pequenos e médios agricultores e os indígenas tem vínculos estabelecidos por quase um século. (No caso dos indígenas é secular). Portanto, a estratégia de desenvolvimento da região deve atender seus anseios e necessidades. Nesse contexto, alguns apontamentos para planejamento e execução de projetos na região devem ser abordados como prioritários.

\section{Estratégias de desenvolvimento para atender as necessidades da maioria da população do Norte do Araguaia}

Diante do exporto, é possível realizar alguns apontamentos, com objetivos qualitativos para serem alcançados, visando um desenvolvimento sustentável na Região do AraguaiaXingu. Buscando o crescimento econômico, mas que consiga incluir a maioria da população; produzindo riquezas, mas que preserve e conserve o meio ambiente; respeite e valorize a cultura e as características sociais da (maioria) população residente na região; enfim, um desenvolvimento que produza sem destruir e/ou degradar; que gere riquezas ao invés de miséria e marginalização; que consiga utilizar o conhecimento popular aliado ao científico, criando tecnologias sociais adaptadas à região. Ou seja, inclusivo, que assimile a dimensão econômica, social, ambiental e cultural.

Frente a esse desafio alguns objetivos qualitativos podem (e devem) ser elucidados. Na questão econômica é central o fortalecimento da atividade pecuarista e de uma agricultura voltada a Soberania Alimentar. Os mosaicos na paisagem das propriedades devem conjugar esses dois objetivos. O desafio é aumentar a produtividade por hectare através da qualidade das pastagens, e a recuperação das áreas degradadas e de preservação permanente (APP’s), fundamentais para quantidade e qualidade da água, e manutenção dos mananciais. É necessário criar e adaptar técnicas e tecnologias, que consigam aumentar a produtividade, em especial no cultivo e manejo das pastagens; e ao mesmo tempo promover a produção de alimentos e produtos demandados na região. A extensão pública se faz essencial, visto que a privada, no modelo atual, é pouco eficiente, pois é realizada "casada" com a venda de produtos (insumos), e que gera, a priori, "conflitos de interesses". 
A responsabilidade dos órgãos públicos de ensino, pesquisa e extensão é criar, desenvolver, aperfeiçoar e/ou melhorar, no que diz respeito as tecnologias e técnicas para desenvolver a agricultura familiar no Norte do Araguaia. Assim como capacitar profissionais que consigam atuar para desenvolver e melhorar a atividade agropecuária na região. Sabendo que pesquisas pontuais e/ou espontâneas dificilmente terão efeito estratégico, e que a tendência é canalização dos recursos materiais e humanos para o meio de produção hegemônico, ou seja, para agricultura empresarial. Para atingir a outra finalidade, ou seja, desenvolver a agricultura familiar e camponesa e indígena regional, é necessário, como um exemplo de política pública a criação de fundos e editais direcionais a essa demanda especifica. Dessa forma, é possível induzir os profissionais do serviço público (e privado) a direcionarem suas energias para a finalidade: melhorar a produção da Agricultura Familiar regional.

Entretanto, para criar editais específicos é necessário um diagnóstico e análise para o Norte do Araguaia, por meio de estudos interdisciplinares e transdisciplinares, que consigam compreender o todo, as características econômicas, sociais, ambientais e culturais. Para tanto é necessário criar grupos de estudos, pesquisas e desenvolvimento estratégico, que consigam mapear, diagnosticar e também de criar e formular estratégias para o desenvolvimento sustentável a curto, médio e longo prazo, através de políticas públicas.

Esse texto poderia tentar esgotar o assunto, formulando através de observações empíricas e dados regionais, como as fontes do IBGE. Mas esse não é o objetivo. Ao contrário, o objetivo do texto é levantar o debate a respeito dos grandes desafios que a região e sua população enfrentará, como exemplo, o êxodo rural e diminuição do trabalho rural, devido a agricultura empresarial e mecanização e automatização das atividades agropecuárias. Como os próprios dados do Censo Agropecuário do IBGE 2017, revelam que houve na última década, a redução dos empregos nas atividades agropecuárias.

A tecnologia é, portanto, não um fim em si. A tecnologia tem o poder de melhorar a qualidade de vida da população ou de piorar. Vejamos um exemplo simples, máquinas grandes e automatizadas reduzem o número de trabalhadores, aumentam o desemprego, consequentemente pioram a qualidade de vida da população como um todo, afinal, menos emprego, mais violência, menor qualidade de vida, menos acesso a serviços essenciais como saúde, saneamento, educação, etc.

Mas, e se o centro estratégico direcionar seus esforços para produção de máquinas de menor porte, para o uso em escalas menores (ou mesmo individuais), adaptadas a condições da família? Essas máquinas podem melhorar a vida das pessoas do campo, melhorando as condições de trabalho e ao mesmo tempo, aumentando a produtividade e a eficiências na 
pequena e média propriedade. Um bom exemplo é a máquina desenvolvida no estado do Pará para coletar o açaí. A pergunta que se lança é: quais esforços, das instituições públicas (e também as privadas) de ensino, pesquisa e extensão estão sendo direcionados (ou canalizados) para melhorar a vida dos pequenos e médios agricultores da Região? Não é preciso grande esforço para encontrar a resposta. O hegemônico (Santos, 2012) tende a absorver para si todos os recursos materiais e humanos. Por isso a necessidade de editais direcionados a cada uma das especificidades, com objetivos qualitativos claros e metas definidas de forma democrática, transparente e participativa.

A democracia, a transparência e o incentivo a participação popular serão fundamentais para promoção do desenvolvimento sustentável da região. Muitos afirmam que "o Norte do Araguaia é uma região rica”. Essa afirmação que é difícil de mensurar e/ou sustentar devido à falta de estudos sobre a economia real da região e de suas respectivas atividades produtivas. A atual situação dessa região, considerando os dados do IBGE (2017), em relação ao aumento da produção, remete, com clareza, que nem sempre a riqueza está junto com emprego equalidade de vida. Basta comparar a produção de riquezas versus a distribuição de riquezas, a quantidade empregos diretos e indiretos (no campo e na cidade) e o salário médio nos municípios com maior quantidade de propriedades com assentados da Agricultura Familiar e os municípios onde é predominante a agricultura empresarial. Essa observação e análise exacerbam os dois modelos de desenvolvimento antagônicos que foram identificados na região. E que são conflituosos, portanto disputam, tanto o território quanto o Estado e seus respectivos recursos, de acordo com seus interesses.

Mas a disputa principal é no campo da narrativa, e a hegemonia tende a (re)produzir sua própria "história" e/ou estória (Santos, 2012), enaltecendo seus méritos vantagens e omitindo as suas contradições fragilidades. Por isso, a necessidade de realizar os estudos e pesquisas, e fundamentalmente, debater a respeito das informações produzidas. Muitas sociedades pagaram custo alto devido à falta de estudos sociais, ambientais e econômicos de sua estrutura e organização. Portanto, é impossível prever ou falar em "região rica" sem estudos, com metodologias sérias e rigorosas, e mais importante, diversas, para ser possível a comparação.

Sobretudo podemos afirmar que a região é rica em diversidade. Apesar dos poucos estudos, as diversas origens da população que aqui ocuparam o território ao longo do século $\mathrm{XX}$, com as que já estavam estabelecidas na região (indígenas e ribeirinhos), nos permitem afirmar que são ricas em diversidade cultural, pela variedade e peculiaridade alimentar, característica próprias de territórios colonizados por várias regiões. 
Riqueza essa, que resgatada e valorizada, podem garantir o desenvolvimento sustentável, inclusive enfrentando problemas como a recuperação de áreas de preservação permanente. O regime pluvial, e toda bacia hidrográfica, pode ser alterada e/ou comprometida ao longo dos anos se esse desafio não for enfrentado. Além de discutir as consequências dos canais de drenagem para o regime pluvial. Mas, existem comitês de bacias hidrográficas entre os municípios da região? No entanto o problema pode vir a ser solução, a própria legislação possibilita alternativas, por exemplo, a recuperação das áreas de preservação permanente utilizando espécies (inclusive exóticas) com potencial uso econômico. Espécies chave, tanto para o uso madeireiro como para não madeireiros, como frutos, sementes, condimentos, aromáticas e medicinais.

A recuperação desse passivo, utilizando as tecnologias já existentes e desenvolvidas na região, como o Sistema Casadão ${ }^{1}$, que garante a recuperação das áreas aliada a geração de renda. Essas tecnologias já existentes se estruturadas e articuladas ao conhecimento científico podem produzir bons resultados: econômicos, sociais, ambientais e culturais. Ressaltando o potencial farmacológico das plantas da região. Com essa finalidade seria imprescindível aliar o resgate e a valorização do conhecimento popular, das pessoas (os raizeiros) da região, - que utilizam diversas plantas como buriti, murici, jatobá, bacaba, copaíba, dentro tantas outras -, junto ao conhecimento científico, para promover uma cadeia produtiva de fármacos, produtos de higiene e cosméticos, com indústria de ponta. Iniciativas dessa natureza seria essencial para a sustentabilidade econômica, a diversificação e dinamização da economia.

A própria atividade do turismo, ou ecoturismo, é uma possibilidade de aliar a preservação e conservação dos recursos naturais com a geração de renda. Para isso, é necessária a criação de ação estratégicas, que vão, desde a capacitação dos envolvidos nessa atividade, até questões mais práticas como o transporte e a hospedagem. A implementação dessas ações requer conhecimento específico, que vão desde administração, economia, logística e meio ambiente.

A educação é, e cada vez mais será, necessária para nossa inserção no disputado mundo do trabalho, cada vez mais tecnológico e globalizado, onde o uso da inteligência artificial, redes neurais, etc., exigem o conhecimento de programação. Mas novamente, a educação em si não é um fim, é um meio, que pode ajudar a melhorar a qualidade de vida das pessoas, como o exemplo citado das máquinas.

A pergunta que se faz aqui é, a escola e sua estrutura organizacional será capaz de capacitar os estudantes para os desafios que se apresentam no bojo do processo de desenvolvimento da região? Sem inovações estruturais, organizacionais estaremos preparados 
para atender ao atual mundo do trabalho? As instituições de ensino conhecem as reais tendências do mercado e as exigências do consumidor? Como é será o mundo do trabalho no século XXI? E as inovações, biotecnologia, nanotecnologia, geotecnologia, redes neurais, inteligência artificial, programação e, seus desdobramentos. E que são ferramentas essenciais para zoneamento e a adoção de boas práticas conservacionistas, através de critérios técnicos e políticos, de uso e manejo do solo, tanto para áreas rurais como urbanas.

${ }^{1}$ Sistema Casadão é uma tecnologia social de Agroflorestas - consorcio de espécies anuais, arbóreas e animais, consorciadas ao longo do tempo e espaço - produtivas desenvolvidas pelos agricultores do Norte do Araguaia.

Ao mesmo tempo as instituições de ensino, pesquisa e extensão, públicas e privadas, devem olhar mais atentamente para a realidade específica da região. Um exemplo clássico, que podemos aqui citar, é o da mandioca. As culturas mais citadas quando indagados os moradores em entrevistas informais é milho e soja. No entanto, se perguntado, as pessoas da região são grandes consumidores de farinha e mandioca. Por que então nunca respondem a produção de mandioca?

Mas somos consumidores de farinha. Criamos gado. Pescamos. Temos diversas plantas nativas que utilizamos para diversos fins - alimento, medicina, condimento, cosmético. Compreender essas características é fundamental para que haja um desenvolvimento realmente sustentável e durável. Ao citar desenvolvimento, parte se do pressuposto que não existe desenvolvimento sem que a finalidade seja sustentável. Muito embora possamos ter e garantir a sustentabilidade de muitas coisas, garantir a sustentabilidade da pobreza, da miséria, da desigualdade econômica e social, da violência. E, inclusive, obter lucro (exorbitantes) com essa "sustentabilidade".

O objetivo desse texto, desde o início foi o de refletir sobre o Norte do Araguaia que queremos para os nossos descendentes. Quando observamos o "desenvolvimento" de outros estados, é possível notar algumas características intrínsecas (e peculiares), por exemplo, a formação de um polo econômico, especializado em serviços e que recebe a maioria dos recursos do estado, rodeado por cidades menores. Essa cidade polo tem ao seu entorno enormes periferias (Santos e Silveira, 2006). Onde há a falta de serviços básicos (saúde, segurança, trabalho/emprego, educação) com qualidade para a maioria da população.

Acreditamos que foi essa observação que norteou esse texto. O mais importante não são as respostas aqui apresentadas. O mais importante aqui, é justamente as perguntas feitas, para que consigamos discuti-las. Fundamentalmente, as perguntas quanto a Araguaia Xingu que queremos para o futuro, o legado que queremos deixar aos nossos descendentes. Para isso é essencial compreender o processo enquanto história, sem fulanizar. Para compreender o 
processo, e os respectivos interesses envolvidos, é necessário fazer as perguntas certas. Entendendo o nosso papel frente a agricultura empresarial e os respectivos interesses das organizações multinacionais e transnacionais envolvidas.

Gostaríamos de poder refletir e debater essas perguntas e dúvidas de maneira mais profunda. Em relação tanto as questões ambientais (solo, hidrografia, clima), sociais (pessoas, instituições de pesquisa e ensino, demografia, culturais) e econômicas (atividades produtivas, rentabilidade, custo da logística), ou seja, de compreender melhor a região Araguaia-Xingu. Para tal objetivo é necessário a articulação das instituições públicas e da iniciativa privada, e a sociedade civil (organizada ou não), e que construam espaços para debater e articular as ações necessárias para o desenvolvimento sustentável do território.

\section{Considerações Finais}

O estudo histórico do Norte do Araguaia possibilitou identificar as principais características econômicas, sociais e ambientais na região Araguaia-Xingu. E através desses realizar apontamentos sobre as estratégias de desenvolvimento territorial.

O território é profundamente marcado pelos assentamentos da Reforma Agrária e a principal atividade econômica é a agropecuária. Foi identificado a disputa de dois conceitos de desenvolvimento, o da agricultura empresarial versus os assentamentos da Reforma Agrária agricultura familiar e indígena. Conceitos que são antagônicos, e, portanto, conflituosos, em que ocorre a disputa, tanto a narrativa quanto os objetivos materiais e estruturais, na consolidação do seu respectivo conceito de "desenvolvimento sustentável".

Nesse contexto, foram analisados alguns desafios do Norte do Araguaia. No que tange o ambiente foi identificado as características na bacia hidrográfica, tendo como fator determinante a pouca declividade que definem o regime hídrico peculiar. E que permitem formar mosaicos e biomas altamente específicos e grande fragilidade. Portanto que requerem atenção especial quando a ocupação, e medidas conservacionista de uso e manejo do solo e dos recursos hídricos.

Nas características sociais prevalecem as várias origens dos migrantes, que chegaram ao território ao longo do século XX. A região necessita de investimentos para maior inclusão social, com maiores oportunidades educacionais, e que estejam preparadas para mercado de trabalho do século XXI.

A economia é baseada nas atividades agropecuárias e de serviços. Com destaque para os dois modelos de desenvolvimento que disputam as formas de uso e ocupação da terra: a 
agricultura empresarial (latifúndio, monocultivo, mecanização e automação da agricultura, com pouca mão-de-obra e barata, e produção em larga escala voltada à exportação) versus a agricultura familiar, camponesa e indígena (assentamentos da Reforma Agrária, mão-de-obra familiar, produção em pequena escala e voltada a abastecer o mercado interno e promover a Soberania Alimentar). Ambos os modelos apresentam vantagens e contradições. Pela forma de ocupação do território voltada a assentamentos da reforma agrária acreditamos que esse é o melhor meio para promoção do desenvolvimento sustentável, tanto pelas questões econômicas e sociais, quanto ambientais e culturais.

Nesta perspectiva acreditamos que as instituições de ensino, pesquisa e extensão, públicas e privadas, devem promover mecanismo, através de políticas públicas, a favorecer o fortalecimento da Agricultura Familiar. Em linhas gerais foram apontados os desafios e oportunidades no atual contexto, de uso e conservação dos solos, como a melhoria e fortalecimento da atividade pecuária e agricultura voltada a Soberania Alimentar; proteção dos mananciais e da biodiversidade, com o desafio da recuperação de áreas degradas e áreas de preservação permanente, utilizando espécies de múltiplos usos, com potencial em castanhas, sementes, medicinal, condimentar e aromáticos, conjugando o conhecimento popular ao conhecimento cientifico acadêmico; e a diversificação e dinamização da economia regional, através do potencial de agroindústrias e industrias de fármacos, além da atividade de turismo, devido elevada beleza cênica do Araguaia-Xingu.

O levantamento histórico e os apontamentos não se esgotam nesse texto, mas que o mesmo possa servir para aprofundar as questões aqui apresentadas em grupos temáticos transdisciplinares. Interelacionando as dimensões ambiental, econômica e social, e cultural, através de políticas públicas, com estratégias, objetivos, metas e ações de curto, médio e longo prazo, voltadas a educação, saúde, segurança, trabalho e lazer, criando assim a oportunidade de promover o desenvolvimento sustentável do Norte do Araguaia.

\section{Referência Bibliográfica}

GARBIN, V. H. Silva, M. J. Silva, A. Plano territorial de desenvolvimento rural sustentável território baixo Araguaia -MT. Brasília: MDA, 2006.

MACHADO, Luiz Carlos Pinheiro. Pastoreio Racional Voisin: tecnologia agroecológica para o $3^{\circ}$ milênio. Editora Expressão Popular, 3ª edição. São Paulo, 2013. 
MARIMON, Beatriz Schwantes et al. Florística dos campos de murundus do Pantanal do Araguaia, Mato Grosso, Brasil. Acta Bot. Bras. Feira de Santana, v. 26, n. 1, p. 181-196, Mar. 2012.

MARTINS, A.K.E., SCHAEFER, C.E.G.R., SILVA, E., SOARES, V.P., CORREAA, G.R. \& MENDONÇA, B.A.F. 2006. Relações solo-geoambiente em áreas de ocorrência de Ipucas na planície do médio Araguaia - Estado do Tocantins. Revista Árvore 30:297-310.

SANTOS, Milton. Por uma Geografia Nova: da crítica da Geografia a uma Geografia Crítica. $6^{\mathrm{a}}$ edição, $2^{\mathrm{a}}$ reimpressão. São Paulo: editora da Universidade de São Paulo, 2012.

SANTOS, Milton e Silveira, Maria Laura. O Brasil: Território e Sociedade no Início do Século XXI. Editora Record, 6ª edição, Rio de Janeiro, 2006.

ZIEGLER, Jean. Destruição em massa: geopolítica da fome. São Paulo: Cortez, 2013.

MAZOYER, Marcel e Roudart, Lurence. História das agriculturas no mundo: do neolítico à crise contemporânea. São Paulo: Editora UNESP; Brasília, DF: NEAD, 2010. 